\title{
Política Nacional de Saúde e a Educação Médica Brasileira
}

\section{Health Policy and the Brazilian Medical Education}

Excelentíssimo Senhor Presidente da Academia N acional de M edicina, D r. Aloysio de Sales Fonseca.

Excelentíssimos Senhores Acadêmicos, prezados colegas de profissão.

D emais autoridades presentes.

Senhoras e Senhores.

Ao mesmo tempo em que é um grande orgulho ser depositário da confiança e consideração do nosso M inistro da Saúde, José Serra, muito me pesa a responsabilidade de representálo nesta solenidade, mais ainda tratando de um assunto de tamanha relevância e de uma platéia tão exigente e seleta.

Q ual a finalidade maior da Educação? Indubitavelmente, transformar a realidade, orientando os rumos da sociedade para 0 pleno gozo das capacidade física e faculdades mentais humanas, em equilíbrio com o seu habitat natural e em busca da felicidade, de forma justa, que é aquela que contempla 0 maior número de indivíduos.

E qual a finalidade maior da Educação M édica? A mesma, acrescida das suas características de manter a saúde da população numa abrangente área de atuação, que vai da promoção da saúde, permeada pela prevenção e tratamento das doenças, até a paliação de sintomas.

Permito-me aqui uma observação, quanto à prática médica, no que tange à paliação de sintomas. Curiosamente, os cuidados paliativos, que são o objeto máximo do nosso juramento hipocrático, pouco são incorporados por nós, médicos, formados sob a ótica da doença como condição inevitável, da terapêutica até de doenças evitáveis e do sucesso profissional com base na erradicação das doenças.

D o ponto de vista do M inistério da Saúde, a Educação $M$ édica no Brasil teria de considerar os problemas de saúde que devem, ou podem, ser evitados e que precisam ser tratados, inclusive paliativamente, decorrentes das grandes modificações ocorridas no nosso País, nos últimos cinqüenta anos.

0 envelhecimento da população; 0 aumento das doenças crônico-degenerativas; o surgimento de novas doenças, como a AIDS, que cursam com 0 aumento de gastos específicos; e o recrudescimento de doenças transmissíveis nas regiões de fronteira e de baixa cobertura de saneamento básico e de vigilância epidemiológica são exemplos de problemas que precisam ser discutidos e praticados nas escolas médicas, na busca de soluções preventivas e terapêuticas.

Dessa responsabilidade a Educação $M$ édica não pode se furtar. A formação médica enfocada exclusivamente em procedimentos diagnóstico-terapêuticos, repetindo a prática de outros países e incorporando acriticamente tecnologias lá desenvolvidas e por eles comercializadas, não tem modificado as taxas de mortalidade pelas doenças crônico-degenerativas, mesmo quando consideradas aquelas que podem ser controladas.

A distorção dessa prática, por sua vez, resulta na estruturação de um sistema de saúde conceitualmente consistente, porém de difícil operacionalização, devido ao grande conflito de interesses que o mergulham em contradições. E cuja discussão, quando a ela se procede, é deturpada pela luta ideológica, político-partidária, ou até mesmo comercial e corporativa, ficando o bem maior, a saúde pública, à margem da sua real importância e necessidades.

Essa situção se agrava, se se recorda que tanto o sistema educacional como o sistema de saúde são financiados, em cerca de $80 \%$, 
por recursos públicos, dado ser o G overno 0 maior financiador e comprador de serviços desses sistemas e o grande mantenedor de instituições próprias de nível superior, municipais, estaduais e federais.

$\mathrm{N}$ a verdade, a M edicina e o sistema de saúde brasileiros apenas expressam os padrões e expectativas da sociedade brasileira, sabidamente marcada por profundas feridas sociais e morais, expressões da desigualdade que há entre os direitos individuais e coletivos. D iferença essa determinada pelos distintos graus de educação e de poder econômico que caracterizam a nossa população.

A prática médica, no Brasil, incorpora tecnologias, amplia custos e tem baixa resolubilidade. Por exemplo, entre nós encontra-se o maior número de aparelhos de tomografia computadorizada per capita, no mundo; e temos verificado o aumento do número de máquinas de hemodiálise, mas não a redução do número de doentes hipertensos.

Frente a este quadro, o que se pode esperar com relação a formação médica?

Aprender é um elemento-chave na educação médica, tendo em vista um mundo mutável, em que os avanços tecnológicos e da informação e as modificações nas relações de trabalho e produção científica exigem que os estudantes sejam ativos no processo da sua própria formação.

Existe uma tendência a acentuar as contradições e a dicotomia entre o processo de formação e a prática profissional, especialmente entre as atividades médico-assistenciais e de saúde coletiva.

Cada vez mais, faz-se necessário sair dos muros da universidade e agir no cenário real, considerando-se que, na realidade dos serviços de saúde, existem demandas e necessidades próprias que precisam ser respondidas de maneira articulada.

É preciso pensar na organização do programa de ensino, levando-se em conta as prioridades identificadas pelos diferentes programas e projetos de promoção, prevenção, detecção precoce, assistência médico-hospitalar, reabilitação da saúde e paliação de sintomas, e não só na lógica da organização de conteúdos pedagógicos. Só assim a escola médica poderá redefinir seu papel social na formação do médico, a partir do que, quase automaticamente, se redefinirá o papel dos demais profissionais da saúde,

O M inistério da Saúde, as Coordenações dos Programas $\mathrm{N}$ acionais de Saúde e 0 Conselho $\mathrm{N}$ acional de Saúde cada vez mais demonstram seu interesse e a intenção de participar junto com as universidades na definição do perfil do médico de que o Brasil precisa.

As Secretarias Estaduais e M unicipais de Saúde, no seu novo papel no SUS, podem ser excelentes parceiras na definição das competências básicas e específicas que devem ser desenvolvidas pelo médico, relacionadas com os problemas de saúde regionais.

A formação médica inicia-se na graduação, continua-se na Residência M édica e em programas de especialização. Cada período deve ter sua terminalidade assegurada, e o profissional deve aprender a aprender para estar sempre buscando, através da educação continuada, se engajar rapidamente nos diferentes programas de saúde brasileiros.

Saibam todos os presentes que a maior dificuldade do M inistério da Saúde na implantação de programas de saúde pública, cuja base maior é a promoção da saúde e a prevenção de doenças, é a indisponibilidade de profissionais da saúde, inclusive médicos, capacitados nas técnicas mais simples, porém não menos importantes, como a relação humana, a anamnese como fonte de identificação de fatores de risco, o aconsel hamento para a manutenção da saúde, o exame físico e a formulação de hipóteses diagnósticas.

Tanto que, a cada programa de controle de câncer, por exemplo, há de se planejar e executar o treinamento em técnicas básicas, como o exame das mamas, biópsias, o toque retal, etc.

Também, torna-se evidente a incompreensão e a alienação do médico no que diz respeito ao sistema de saúde, no qual se insere sem consciência de como esse sistema é estruturado e do que representa 0 ato médico dentro dele.

Isto porque o médico ultimamente formado pelas escolas médicas tem dificuldades de cuidar do paciente; pratica uma M edicina técnica e intervencionista; e é pouco resolutivo.

Ele tem dificuldade, também, de entender e de articular as ações de promoção da saúde e prevenção de doenças, que são de abrangência coletiva, com a prática médicoassistencial, que é individual. Por isso, torna- 
se incapaz de atender as necessidades da comunidade e dos programas e serviços, e sofre pelo julgamento de uma sociedade que o exige capaz e intelectualmente superior, senão perfeito.

A descrição de um novo perfil para o médico de que o Brasil necessita só se dará se o problema for enfrentado junto entre a escola médica e os serviços de saúde.

A articulação de pólos de capacitação regionais, envolvendo as Universidades e oS serviços de saúde, incluídos em seu planejamento estratégico e suas metas a curto, médio e longo prazo poderão ser um novo referencial para a formação adequada do profissional.

Do ponto de vista pedagógico, importa definir as competências básicas para a formação de um médico, com o término na graduação. Para tanto as seguintes teriam de ser consideradas:

- Reconhecer os principais problemas de saúde dos brasileiros, identificando os fatores de risco e as doenças mais freqüentes nas diferentes regiões do país.

- Conhecer as condutas diagnósticas e terapêuticas padrões para cada uma dessas doenças.

- Conhecer a organização dos serviços de saúde brasileiros, suas controvérsias, conflitos e dilemas.

- Ampliar a consciência de sua responsabilidade social com relação ao cuidado da saúde da população.

- Realizar uma história clínica adequada, reconhecendo aspectos da história pregressa, familiar e psicossocial que predispõem este indivíduo a doenças.

- Realizar o exame físico completo do paciente, solicitando com racionalidade os exames complementares necessários.

- Conhecer o custo dos exames solicitados, buscando relacioná-los com a necessidade e benefício para o paciente.

- Registrar de forma completa os dados obtidos, valorizando o prontuário médico e a geração de informações em saúde.

- Realizar o planejamento terapêutico para o paciente considerando, indicações, limitações dos serviços, disponibilidade de procedimentos, eficácia do tratamento, e atendimento do paciente nos diferentes níveis de complexidade do sistema de saúde.

- Reconhecer a importância da equipe multidisciplinar para a resolubilidade do serviço.

- Ter condições de atender e tratar os principais problemas médicos de pacientes terminais.

- Aconselhar o paciente, os parentes e a comunidade quanto a prevenção, diagnóstico e terapias das doenças prevalentes.

- Capacitar-se para produzir relatórios, comunicados e artigos científicos sobre a sua prática e experiência.

A criação de comissões, envolvendo membros das U niversidades e Secretarias e Serviços de Saúde para a definição de programas de ensino voltados para a realidade nacional, deve ser cada vez mais uma prática de planejamento na área da educação médica.

D eve ser buscada uma maior participação do M inistério da Saúde, por conta de seus Programas e Projetos, na proposição de Programas de Ensino Integrado para a formação médica. Também, devem ser criados programas integrados de ensino-serviço, envolvendo os profissionais de saúde e os gerentes estaduais e municipais de programas, na definição de competências especificas a serem desenvolvidas pelas U niversidades relativas à pratica médica.

D a mesma forma, deve haver um maior incentivo para as escolas médicas de Universidades Federais participarem como pólos regionais de formação, especialização e educação continuada dos profissionais de saúde que atuam na sua região ou estado.

Muito ajudaria se houvesse uma maior utilização nos programas de ensino médico dos materiais educativos, informações, legislação, estimativas e levantamentos epidemiológicos desenvolvidos pelo M inistério da Saúde.

E este é um trabalho que depende do empenho de muitos setores. A escola médica não pode ser a única responsável pela Educação $M$ édica, já que não existe médico sem sistema de saúde; não existe sistema de saúde sem normas estruturadoras e operacionais; não existem normas sem a experiência nem uma prática médica responsável.

Muito obrigado.

\section{Jacob Kligerman}

Diretor Geral do Instituto Nacional de Câncer General-Director of the Brazilian National Cancer Institute 